\title{
O SERVIÇO NACIONAL DE INFORMAÇÕES (SNI): O SINDICALISMO EM PERNAMBUCO COMO ALVO (1964-1967)
} NATIONAL INFORMATIONS SERVICE (SNI): THE UNIONISM IN PERNAMBUCO TARGET (1964-1967)

\author{
Dmitri Felix do Nascimento ${ }^{201}$
}

Resumo: Após o golpe militar de 1964 e a queda do Governo João Goulart, as Forças Armadas se apressaram na formação de um aparato de repressão, um serviço secreto, que pudesse servir aos interesses dos detentores do regime. Foi preciso a aprovação do projeto de lei nº 4.341 de junho de 1964 pelo Congresso Nacional engessado pela ditadura nas mãos do Presidente Castelo Branco que criava assim o Serviço Nacional de Informações (SNI). Um dos seus objetivos seria construir uma ampla rede, uma comunidade de informações, que pudesse controlar as ações dos inimigos do regime, a partir da colaboração e subordinação dos Ministérios Civis, Forças Armadas, Judiciário, Autarquias e Polícias Estaduais. As entidades intersindicais, como o Conselho Sindical dos Trabalhadores (CONSINTRA) hegemonizada pelos militantes comunistas foi um dos alvos do SNI. A partir de documentos recém abertos é possível entender parte do modu operandi do serviço secreto brasileiro.

Palavras-chave: Sindicalismo, Golpe militar de 1964 - Brasil, SNI.

\begin{abstract}
After the military coup of 1964 and the fall of João Goulart government, the Army rushed in the formation of a repressive apparatus, an information service that could serve the interests of the holders of the regime. Approval of the draft law $n^{0} .4341$ of June 1964 by Congress plastered by the dictatorship in the hands of President Castelo Branco thus creating the National Intelligence Service (SNI). One of his goals was to build a large network, a community of information, which could control the actions of the enemies of the regime, with the collaboration and subordination of Civil Ministries, Army, Justice, Local Authorities and State Police. The unions such as the Trade Union of Workers (CONSINTRA) hegemonized by the communist militants was a target of SNI. From documents newly opened is possible see part of the modu operandi of Brazilian secret service.
\end{abstract}

Keywords: Unionism - Pernambuco, Military Coup 1964 - Brazil, SNI

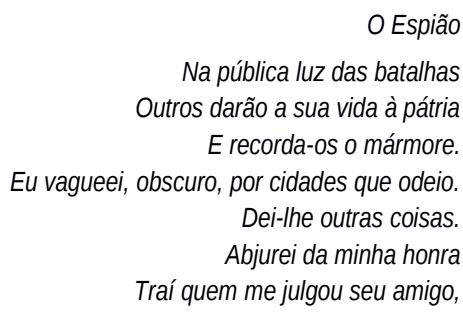

2011 Doutorando pelo Instituto de Ciências Sociais da Universidade de Lisboa (UL) no programa de Doutoramento em Política Comparada na linha de Relações Internacionais. Pesquisador CAPES. Mestre pela Pós-Graduação em História da Universidade Federal de Pernambuco (UFPE). Graduado em História pela Universidade Federal da Paraíba (UFPB). 
Comprei consciência, Abominei o nome da minha pátria Resignei-me à infâmia.

Jorge Luís Borges

Apesar de uma determinada corrente da historiografia contemporânea sobre o período da ditadura militar tentar oferecer uma leitura "revisionista"202 dos fatores, causas, permanências e justificativas do golpe de 1964, tentar se basear em três teses como "a mais moderna interpretação do golpe" que: "1) 'A esquerda e direita foram igualmente responsáveis'; 2), na verdade, 'havia dois golpes em curso' nos idos de 1964; 3) a resistência à ditadura não passou de um mito" ${ }^{203}$, tentaremos neste artigo evidenciar uma das lacunas (ou esquecimento propositivo) desta interpretação por demasiada contraditória.

As justificativas que tentam apresentar "a noção de uma classe trabalhadora passiva e mal organizada"204 assim como a de um sindicalismo "afastado das bases e feito na cúpula" ${ }^{205}$ contraria um dos fatores primordiais das evidências históricas mais marcantes deste período: 0 fator avassalador da repressão do aparato militar contra os setores populares e sindicais da sociedade brasileira, e a implementação de uma política econômica baseada na máxima exploração do trabalho e na retirada de direitos trabalhistas.

E é com ênfase nestas evidências que reforçaremos uma posição histórica com base na recente abertura de parte dos arquivos da ditadura militar em posse do Estado brasileiro, somado ao momento político do país que se desafia a compreender o regime autoritário com a criação, mesmo que de forma limitada, da Comissão Nacional da Verdade ${ }^{206}$ (CNV) em 2012; com isto torna-se possível e necessário

\footnotetext{
${ }^{202}$ FUIGUEIREDO, Argelina C. Democracia ou reformas? Alternativas democráticas à crise política, 1961-1964. Rio de Janeiro: Paz e Terra, 1993.

FERREIRA, Jorge (org). O populismo e sua história: debate à crítica. Rio de Janeiro: Civilização Brasileira, 2001.

REIS, Daniel Aarão. Ditadura, anistia e reconciliação. Estudos Históricos. Rio de Janeiro: vol.23, n.45, p.171-186, jan/jun. 2010.

ROLLEMBERG, Denise (org). A construção social dos regimes autoritários. Brasil e América Latina. Rio de Janeiro: Civilização Brasileira, 2010.

${ }^{203}$ MELO, Demian Bezerra de. 0 golpe de 1964 e meio século de controvérsias: o estado atual da questão. In: $A$ miséria da historiografia: uma crítica ao revisionismo contemporâneo. MELO, Demian Bezerra de (org). Rio de Janeiro: Consequência, 2014, p. 158.

204 Idem, p.187.

${ }^{205}$ Idem.

206 A Comissão Nacional da Verdade foi criada pela Lei 12528/2011 e instituída em 16 de maio de 2012. A CNV tem por finalidade apurar graves violações de Direitos Humanos ocorridas entre 18 de setembro de 1946 e 5 de outubro de 1988.
} 
realizar estudos que tendem a aprofundar o debate sobre a experiência ditatorial no Brasil confrontando com novas fontes. ${ }^{207}$

Desta forma, procuramos explanar neste artigo algumas ações do Serviço Nacional de Informações (SNI), em conjunto com os braços de repressão (polícia militar, judiciário, ministérios), nos primeiro anos da ditadura frente ao sindicalismo combativo em Pernambuco.

Assim como foi feita a repressão sistêmica às entidades estudantis e ligas camponesas, tentaremos entender a rede de informações que se construía na perseguição aos militantes da intersindical, Conselho Sindical dos Trabalhadores (CONSINTRA), direcionada principalmente aos militantes comunistas vinculados aos sindicatos dos bancários e dos portuários.

Buscamos construir a partir das fontes selecionadas no Arquivo Nacional do Rio de Janeiro tendo por base os dados da Divisão de Segurança de Informações do Ministério da Justiça (DSI/MJ), um estudo contextualizado onde encontramos parte do material disponível sobre os serviços de informações, dialogando com entrevistas e relatos.

Também objetivamos elucidar as ações do serviço secreto brasileiro e da rede de informações criada, a partir de seus tentáculos no estado autoritário, e abrir portas sobre fatos que antes não se dispunham até então na historiografia, tal como resgatar versões a serem construídas com novos olhares.

\section{ESTRUTURAÇÃO DA REDE DE ESPIONAGEM EM PERNAMBUCO}

A atuação do SNI em nível nacional foi realizada nas várias esferas do poder, podendo-se dizer que foi se constituindo simultaneamente, por fora do Estado, clandestinamente pelo complexo Instituto de Pesquisa e Estudos Sociais/Instituto Brasileiro de Ação Democrática (IPES/IBAD), até se instaurar por completo dentro do Estado brasileiro com base na formação ideológica realizada pela ESG (Escola Superior de Guerra) e nas estruturas de espionagem construídas pelo extinto SFICl (Serviço Federal de

${ }^{207}$ Com base na lei n. 12.527/2011 de 18 de novembro, a Lei de acesso à informação, abriram-se portas jurídicas para 0 acesso aos documentos da ditadura militar, e com o decreto n. 7.724 de 16 de maio 2012, foi reforçada esta abertura com os editais redigidos pelo Arquivo Nacional, AN n. 1 de 17 de maio de 2012, AN n. 2 de 31 de 31 de maio 2012 e AN n. 3 de 29 de junho 2012. 
Informações e Contra-Informações), sem esquecermos, sobretudo, da gênese militar que estruturou 0 Serviço, alinhados à Doutrina de Segurança Nacional (DSN).

A partir dos estudos de Dreyfuss e de outros autores, apontamos que "O SNI foi uma inovação fundamental introduzida pela administração pós-64"208 e, que, "O SNI se propôs a tornar-se um centro influente na formulação de diretrizes em todas as áreas da vida social, política e militar brasileira". ${ }^{209}$

Entender como foi realizada a estruturação e a atuação do SNI na ditadura não é uma tarefa fácil, por dois principais motivos: poucos trabalhos publicados sobre o assunto, e principalmente, a falta de fontes. Uma das perguntas que fazemos sobre o assunto é: como um serviço secreto sem antecedentes em nossa história com dispositivos de poder de alcance nacional foi rapidamente ramificado nas estruturas do Estado brasileiro e na sociedade?

Após a sua criação pelo projeto de lei no 1.968, baseado no decreto lei 4341 de 13 de junho de 1964, o SNI pode exercer o poder "infinito" e criar agências regionais onde fosse preciso. As primeiras agências foram instaladas em São Paulo, Minas Gerais, Brasília, Rio Grande do Sul, Paraná e Pernambuco, sendo a agência central (AC) no Rio de Janeiro.

É importante frisarmos que no processo de construção do SNI a articulação entre o poder central e as estruturas federais e regionais (e empresas privadas) colocavam em funcionamento uma rede de poder que, para além das trocas de informações entre si, agilizavam uma cadeia na qual se processava o quadro geral das perseguições e da vigilância aos setores contestadores do regime. É possível entender a atuação do SNI com base na rede de espionagem que estava inserida nas relações junto às diversas instituições que passavam a operar no comando hierárquico reproduzido pela natureza de caráter militar do regime.

Ao analisarmos como esta atuação foi direcionada no Estado de Pernambuco entre os anos 19641967, durante o Governo Castelo Branco, abordamos um conjunto limitado de ações sobre o sindicalismo que é possível ter acesso a este momento. Ao fazermos essa procura sistemática a fim de esclarecer parte da atuação do regime militar em Pernambuco encontramos no acervo da Divisão de Segurança de Informações do Ministério da Justiça (DSI/MJ) documentos que nos ajudam na análise deste trabalho.

\footnotetext{
${ }^{208}$ DREIFUSS, René Armand. 1964: a conquista do Estado - Ação Política, poder e golpe de classe. Petrópolis: Vozes, 1981, p. 421. ${ }^{209}$ Idem.
} 
As estruturas das DSI'S foram criadas em 1967 após três anos da criação do SNI em 1964, nos últimos meses do governo Castelo Branco a fim de reestruturar a agência com novos meios de inserção política nas estruturas do Estado:

Em julho de 1967 foi aprovado um novo regulamento para o SNI, que teve sua estrutura ampliada. $O$ decreto transformou as antigas Seções de Segurança Nacional dos Ministérios Civis - órgãos complementares do Conselho de Segurança Nacional - em Divisão de Segurança e Informações (DSI'S). As ASI's, Assessorias de Segurança e Informações, instaladas em diversas instituições públicas, e as DSI's, nos ministérios civis, ficaram como órgãos complementares que compunham o Serviço Nacional de Informações. ${ }^{210}$

Podemos indagar como que os documentos produzidos pelo SNI e suas filiais, no período de 196467, foram parar no DSI/MJ, observando que estes documentos foram levantados na fase inicial de estruturação do SNI. O historiador Carlos Fico ${ }^{6}$ explica esta aparente dispersão dos documentos da comunidade de informações:

Havia grande troca de papéis entre os diversos órgãos de segurança e de informações: as DSI dos diversos ministérios, o CIE (Centro de Informações do Exército), o CISA (Centro de Informações de Segurança da Aeronáutica), o CENIMAR (Centro de Informações da Marinha), o SNI (Serviço Nacional de Informações), a CGI (Comissão Geral de Investigações), as segundas seções das unidades militares, as delegacias de ordem política e social (DOPS) vinculadas às secretarias estaduais de segurança etc. ${ }^{211 .}$

Com o recrudescimento do regime após 1968, seguido pelo Ato Institucional número 5 antecedido pela posse do general Costa e Silva em 1967, e o começo das ações de luta armada, como as guerrilhas no campo e na cidade; a operacionalidade e a máquina de guerra do regime sofrem alterações, alterando e diversificando de imediato as atribuições da comunidade de informações e do SNI. Desta forma, há muitos mais documentos que foram reproduzidos após este período, com a reestruturação do SNI.

Então, os processos que tivemos contato, possibilita uma visão crítica sobre a sistematização da repressão em Pernambuco no período Castelo Branco, abordando uma amostragem das ações da comunidade de informações na perseguição aos sujeitos políticos, no período ditatorial.

\footnotetext{
${ }^{210}$ ANTUNES, Priscila Carlos Brandão. SNI \& ABIN: Uma leitura da atuação dos Serviços Secretos Brasileiros ao longo do Século XX. Rio de Janeiro: FGV editora, 2001, p. 54.

${ }^{211}$ FICO, Carlos. Como eles agiam. Rio de Janeiro: Record, 2001.p. 27.
} 
Nestes processos, conseguimos acessar uma quantidade de casos diversos, envolvendo a perseguição e investigação contra lideranças populares, sindicais, partidárias, estudantes, operários, religiosos, e estrangeiros, acusados de inimigos do regime. Desta forma, é possível encontrar uma relação de registros com alguns fatos já conhecidos, porém, mais especificamente permitindo entender o modo de funcionalidade, o caráter e as ações que o regime foi moldando para o uso da comunidade de informações em seus primeiros anos, condicionando os perseguidos políticos a uma cadeia de interesses do poder, levando a investigações que resultavam, na maioria das vezes, em prisão, tortura, fuga do país, e/ou morte.

Assim como outras capitais do Brasil, Recife foi uma das primeiras onde foi instalada uma Agência do SNI, porém sabemos que, por ser o Estado de Pernambuco um dos quais as mobilizações populares apresentavam maior grau de radicalidade, os desafios também eram enormes para cumprir as funções para qual foi criada. Desta forma, a agência agia conjuntamente com as Forças Armadas e a Polícia Militar, mas, sobretudo, com o Centro de Informações da Marinha (CENIMAR), agência que tinha mais experiência de investigação aos comunistas e agentes formados para esse tipo de trabalho.

Constatamos que dentre as tarefas que 0 SNI deveria realizar eram prioritárias: 0 desmantelamento das Ligas Camponesas, do Partido Comunista Brasileiro e dos sindicatos a ele vinculado, assim como o acompanhamento das atividades de alguns padres e sacerdotes da Igreja Católica, e, a perseguição aos antigos apoiadores do governador Miguel Arraes.

As estruturas de repressão vinculavam-se à agência coletando dados das perseguições e enviando relatórios que produzissem processos jurídicos (IPMs) daí repassada a outros órgãos de repressão, ficando disponível a consulta ao Presidente e ao Conselho de Segurança Nacional (CSN). 0 modus operandi que observamos nos documentos esclarece algumas operações de investigações de caráter Secreto ou Confidencial Urgente (como eram classificados os documentos) que eram direcionados, na maioria dos casos, de maneiras distintas.

A Agência Central do SNI criava seus tentáculos nos setores estatais a partir de três Seções: a Seção de Informações Estratégicas, a Seção de Segurança Interna e a Seção de Operações Especiais. Com a criação das Seções de Segurança Interna foi possível o controle de atividades dos ministérios, possibilitando compreender em parte algumas dessas operações. 
Observamos que as ações de investigações que eram realizadas em conjunto com os órgãos de repressão eram encaminhadas às Seções de Segurança Interna que, em parceria com a Seção de Segurança Nacional do Ministério da Justiça e Negócios Interiores, chegava ao SNI. Em outros documentos, identificamos investigações feitas pelo CENIMAR, encaminhadas para a Seção de Segurança do Ministério da Educação e reencaminhadas para o SNI, ou então, investigações perpetradas pela Secretaria de Segurança Pública do Estado de Pernambuco encaminhadas para o IV Exército, depois para a Seção de Segurança Nacional do Ministério da Justiça, ou para outras Seções de Ministérios da Previdência ou dos Transportes, por exemplo.

Sabemos que o período de 1964-1967 foi a fase de implementação deste sistema. A dinâmica desta cadeia tinha como principal objetivo fazer acelerar as informações primordiais para assessorar o SNI, qualificando a repressão e sua ordem de comando.

A Agência Regional (ARE) do SNI em Recife-PE ficava, segundo relatos, no prédio dos Correios na Avenida Guararapes. Nesta localidade central da cidade, era possível (e mais prático) violar correspondências e realizar escutas clandestinas, grampos, na rede de telefonia envolvendo os suspeitos. Não era apenas uma mera estrutura física ou um mero departamento, era o epicentro do sistema que acabara de se estabelecer, com fome de informações sobre todas as movimentações que circulavam dentro e fora das estruturas do Estado, em seus âmbitos federal e estadual.

A Polícia, autarquias federais, ministérios, governos estaduais e municipais, exército, marinha, aeronáutica, universidade, promotoria, fórum, delegacia, repartições públicas do executivo, legislativo e judiciário; enfim, agora havia um epicentro criado para receber todas as movimentações concretas, suspeitas ou imagináveis dos opositores do regime. Era preciso fichar, processar e investigar tudo o quanto possível, criar a rede de informações, alimentar a fome do monstro, do Ministério do Silêncio ${ }^{212}$, do SNI.

O SNI foi formado por militares e mantinha sua estrutura hierárquica como tal, então seriam os quadros das forças armadas que deveriam formar seu corpo funcional e seus agentes, porém o modo de operacionalidade e controle iria para além da formação do quartel.

De acordo com o histórico de alguns militares que atuaram em Pernambuco, podemos apontar alguns indícios com base em fontes e relatos, de que a formação e estruturação do SNI nos primeiros anos

212 FIGUEIREDO, Lucas. Ministério do Silêncio: A história do serviço secreto brasileiro de Washington Luís a Lula- 1927-2005. Rio de Janeiro: Ed. Record, 2005. 
da ditadura passaram por um conjunto de militares que tiveram uma formação fora do país e assim ajudaram de alguma forma na estruturação da comunidade de informações no Estado.

O primeiro chefe do extinto Serviço Federal de Informações e Contra-Informações (SFICI) foi 0 General Humberto de Souza Melo, oficial que atuou como Secretário de Segurança Pública e Comandante da Polícia Militar de Pernambuco assim como interventor federal após o golpe. Humberto de Souza fez parte do grupo seleto que criou as bases para a formação do SNI, frequentando cursos nos EUA, na CIA, e no serviço secreto inglês. Já como general, após seu período como interventor em Pernambuco, foi indicado por Castelo Branco para assumir a Comissão Geral de Inquéritos Policial-Militar, responsável pelos processos de punições e expurgos.

Com base no Projeto Brasil: Nunca Mai ${ }^{\mathrm{j} 213}$, encontramos alguns nomes de oficiais que atuaram em Pernambuco e que foram responsáveis por torturas, em seus históricos conseguimos observar a formação nos cursos de inteligência nos EUA.

O Coronel do Exército Hélio Lima Ibiapina, o conhecido e temido torturador da $7^{\mathrm{a}}$ região militar em Recife, cursou a Escola das Américas (United States Army School of the Americas-USARSA) no Panamá, escola gerenciada pelo exército americano direcionada para a formação de militares latino-americanos para desempenharem a luta contra o comunismo em seus países. Segundo relatos, Hélio Ibiapina teve uma formação inicial como agente secreto, ainda como Tenente Coronel, em 1966, diplomando-se como "Millatry Intelligence Phase1" (Inteligência Militar fase 1).

Sobre o Major do Exército Bismark Baracuhy Amancio, há registros de sua atuação no Espírito Santo, Rio de Janeiro e Pernambuco. Há uma denúncia em Pernambuco no ano de 1965 que o coloca como participante de membro de escolta. Também foi aluno da Escola das Américas, em 1967, diplomando-se em "Military Intelligence - Phase II"(Inteligência Militar fase 2).

Os cursos não eram restritos apenas a militares, mas a membros das polícias militares também. É o caso do soldado da Polícia Militar de Pernambuco, José Gomes da Silva, que atuava como colaborador e informante. Foi aluno da Escola das Américas, em 1969, como $2^{\circ}$ Sargento, diplomando-se em "Military Police"(Polícia Militar).

${ }^{213}$ Brasil: Nunca mais - um relato para a história. Petrópolis: Editora Vozes, ga edição, 1985. 
O histórico da formação político-ideológico e técnico dos militares brasileiros visando a criação das agências de informações e do SNI por muito tempo permanecia na "obscuridade", porém, como nos coloca Samantha Quadrat ${ }^{214}$, era algo prioritário nas camadas superiores do oficialato com profunda relação com aparelhos de inteligência de outros países, em especial com os EUA, França e Inglaterra.

Estes são apenas alguns nomes que conseguimos elencar a partir dos arquivos. A formação na área de inteligência era vital para a consolidação do SNI, era preciso enfim profissionalizar a força militar para aperfeiçoar o Serviço. Percebemos, enfim, que muitos destes militares foram vitais para o sistema.

Segue-se então a sistematização dos processos de investigação que achamos viáveis de serem trabalhados, considerando estes como parte de um panorama sobre a forma de repressão, sistematizada e institucionalizada no aparelho de controle e vigilância instaurada com o objetivo de desmantelar setores da sociedade civil brasileira, e em especial sobre o sindicalismo.

\section{AÇÃO INTEGRADA CONTRA O SINDICALISMO COMBATIVO}

Uma das principais organizações sindicais em que se aglutinavam diferentes partidos e setores progressistas populares a fim de dar unidade a várias categorias de trabalhadores era o Conselho Sindical de Trabalhadores (CONSINTRA). O CONSINTRA participava na organização das greves e das lutas econômicas em geral, como também das lutas políticas mais marcantes no país e no estado. Fato ocorrido foi sua posição pela defesa da legalidade e posse de João Goulart, em agosto 1961, quando 0 CONSINTRA decretou uma greve geral em apoio a Goulart, ocasionando a prisão de muito de seus líderes.

O CONSINTRA foi fundado em 1959 a partir do I Congresso dos Trabalhadores do Norte e Nordeste. Havia outras organizações intersindicais no estado como o Conselho Consultivo dos Trabalhadores de Pernambuco e o Pacto Intersindical dos Trabalhadores de Pernambuco. O objetivo principal destas organizações era além de agregar os vários setores e categorias dos trabalhadores, fomentar o debate, o estudo e defesa das reivindicações conjuntas, contribuindo assim para unificar a oposição frente às autoridades e ao empresariado. O CONSINTRA serviria de contraponto, garantindo autonomia aos sindicatos a ela filiada, para que estes não pudessem ser engessados pela intersindical ${ }^{214}$ QUADRAT, Samantha Viz. A preparação dos agentes de informação e a ditadura civil-militar no Brasil (1964-1985). Belo Horizonte: Varia História,v. 28, nº 47. 
burocratizada que era o Conselho Consultivo dos Trabalhadores, quanto para coordenar uma oposição frente à entidade patronal, 0 Conselho Superior das Classes Produtoras, a CONCLAP.

O PCB (Partido Comunista Brasileiro) em Pernambuco exercia uma forte influência no sindicalismo e setores populares, chegando a ser um dos mais atuantes do país. Mesmo na ilegalidade, possuía uma significativa inserção em vários setores da sociedade, como sindicatos urbanos e rurais, estudantes, e setores do Governo Miguel Arraes. Ao iniciar a repressão mais rigorosa em 1964, o PCB entra numa crise por várias razões políticas. Muito já foi estudado sobre as leituras conjunturais que o PCB defendera sobre as razões do golpe de 64 e as ações que a organização teria que realizar a partir daquele momento.

Os setores populares e as esquerdas depois do golpe de 64 e das resoluções do PCB, nunca mais seriam os mesmos, como coloca Marcelo Ridenti:

Com 0 golpe, as esquerdas ficaram socialmente isoladas, disseminou-se uma crise sem precedentes de representação dos partidos tradicionais de esquerda, defensores da revolução dentro da ordem institucional. Era o caso especialmente do PCB - que era ilegal, porém atuava com relativa desenvoltura até 1964 -, também da esquerda católica, de outros grupos menores e ainda da corrente de esquerda nacionalista que integrava o Partido Trabalhista Brasileiro (PTB). ${ }^{215}$

Observamos que, logo após o golpe de 64, 0 aparato de repressão no Estado de Pernambuco não estava em seu ápice de organização, o SNI também não possuía estrutura, recursos e nem agentes suficientes para desenvolver a repressão, como ocorreu anos depois. Desta maneira, a velha estrutura pré64 tomava os asfaltos e enrijecia o Estado, principalmente a partir das ações conjuntas entre a polícia estadual, o judiciário, as Forças Armadas, os setores das Seções de Segurança Nacional e suas Seções de Informações (SIs) dos Ministérios, forjando, assim, o aparato repressivo nos primeiros anos da ditadura.

A grande diferença é que nesta nova conjuntura a circulação de informações e a operacionalidade eram introduzidas numa outra lógica, a de um centro de comando político-militar, o Estado Maior das Forças Armadas (EMFA), e a de um centro estratégico de absorção das informações prioritárias, que assessorava diretamente o General Presidente da República, o SNI.

Em ambos os casos de perseguição aos sindicalistas em Recife, o processo policial gerado nas delegacias da Secretaria de Segurança Pública do Estado era apenas o começo de um longo processo

${ }^{215}$ RIDENTI, Marcelo. Esquerdas revolucionárias armadas nos anos 1960-1970. In: Ferreira, Jorge e Reis, Daniel(org) Aarão. Revolução e democracia(1964-...). Rio de Janeiro: Civilização brasileira, 2007, p.27. 
que se articulava com a Seção de Informações (SI) do Ministério de Justiça e Negócios de Interiores, a qual repassava para outras Seções, como a SI do Ministério do Trabalho, e por fim, era enviada ao SNI.

A Polícia Militar se empenhava em várias frentes para ajudar o Exército e o SNI na missão de desmantelar os sindicatos. E umas dessas frentes era a repressão da organização sindical com influência dos comunistas. A região metropolitana do Recife com os municípios Jaboatão dos Guararapes e Paulista, possuía quantidades de fábricas e indústrias que possibilitavam a criação de sindicatos voltados para as lutas operárias e reivindicações de melhorias para os trabalhadores urbanos. Em Recife, os setores dos servidores públicos, portuários, comerciários, gráficos, bancários e ferroviários eram os mais atuantes na luta econômica pela melhoria de salários.

No golpe de 64 em Pernambuco, a Polícia Militar junto ao Exército fecharam várias sedes sindicais vinculadas ao CONSINTRA, e estes, por sua vez, não conseguiram resistir. A resistência popular desaguou frente à espera de armas que não chegara e de um comando que não houve ${ }^{216}$. Mesmo sem êxito na tentativa de uma greve geral puxada conjuntamente com a Confederação Geral dos Trabalhadores (CGT), algumas greves setoriais foram lançadas, como a do Porto do Recife e da Rede Ferroviária.

Algumas obras tratam da perseguição aos sindicatos no Brasil, como a obra de Marcos Santana ${ }^{217}$, porém sobre o papel das agências de inteligência nesta repressão em Pernambuco há poucos trabalhos específicos sobre este tema.

Entre os processos encontrados, o que nos chama mais atenção foram as investigações sobre 0 movimento sindical, e respectivamente, aos militantes do PCB que estavam inseridos nas atividades políticas dos sindicatos.

O que acreditamos ser a primeira fase, ou a fase de estruturação do SNI no Estado de Pernambuco entre os anos de 1964-67, compreendendo a fase de absorção das informações que havia nos setores já estruturados da repressão, a Polícia Militar e a Justiça exerceram um importante papel tanto no aprisionamento quanto no fichamento dos perseguidos políticos. Os delegados, promotores, juízes, despachavam seus processos direcionados para uma Seção de Informação (SI) e deste para o SNI.

\footnotetext{
${ }^{216}$ JACCOUD, Luciana de Barros. Movimentos sociais e crise política em Pernambuco - 1955-1968. Recife: Editora Massangana, 1990. p.14.

${ }^{217}$ SANTANA, Marcos Aurélio. Homens partidos: comunistas e sindicatos no Brasil. São Paulo: Ed. Boitempo, 2001.
} 
Um destes processos diz respeito à denúncia sobre a atuação de Cícero Targino Dantas, Cícero Gomes da Silva e João Messias da Silva, militantes do Partido Comunista, nos movimentos grevistas do Recife (PE), com o apoio do Conselho Sindical dos Trabalhadores (CONSINTRA) - 08/11/1965 ${ }^{218}$.

Este documento é elaborado com base nas investigações policiais e redigido pela Procuradoria Geral do Estado na $3^{\circ}$ Promotoria Pública da Capital, endereçado primeiramente ao Juiz da $3^{\circ}$ Vara Criminal da Capital. O conteúdo deste processo resumidamente evidencia que os crimes que estes militantes mencionados praticaram era o crime de subversão com base na Lei de Segurança Nacional. Os militantes são indiciados tanto pelo histórico, quanto pelas atividades no Porto do Recife na organização de greves e no recebimento de dinheiro pelo CONSINTRA.

O que nos impressiona neste processo é o sentido abertamente ideológico anticomunista do Procurador do Estado, os argumentos utilizados é uma amostra da mentalidade conservadora que identificava os militantes comunistas como "prosélitos do credo moscovita" acrescentando "daí, o inusitado interesse do marxismo em difundir a sua ideologia através das eficientes drogas manipuladas, com incomparável perícia, pelos exímios esculápios comunistas nos laboratórios bolchevista". ${ }^{219}$

Desta forma o Procurador do Estado, Ananias Tavares de Souza Campos, descreve as causas em que se baseia como atos criminosos:

A doutrinação, a propaganda, o proselitismo, a difusão, a catequese, o convencimento, em suma, a vontade indisfarçável de pretender, através da propagação pública de ideologia marxista, substituir o regime democrático pelo regime comunista. Hão[sic] se venha, pois, argumentar que essa espécie de divulgação da idéia não constitui delito. ${ }^{220}$

O crime então, segundo o Procurador, poderia ser comparado ao "crime de aliciamento de menores". O processo destes três sindicalistas que foram presos e levados ao IV Exército em 64 seria concluído pelo Procurador em setembro de 65.

Outras impressionantes justificativas com base na postura política da qual se baseia o Promotor, reside na suposta conspiração mundial arquitetada pelos comunistas resultando assim na visão dualista do mundo. Para o Promotor, as campanhas realizadas pelos comunistas como A nacionalização do Petróleo,

\footnotetext{
${ }^{218}$ BR.AN,RIO.TT.O.MCP.15.

219 Idem.

${ }^{220}$ Idem.
} 
Reformas de base, Nacionalização dos transportes, Neutralização da política externa, Encampação das empresas estrangeiras, são formas do comunismo internacional de realizar sua influência no Brasil.

Argumenta que o mundo estava dividido em duas partes distintas e irreconciliáveis, o mundo cristão e o não cristão, atribuindo como falsas as palavras atribuída a Lênin sobre a conciliação entre 0 cristianismo e o comunismo. Um ataque sutil do Promotor à visão refletida do Concílio Vaticano II e a Teologia da Libertação.

Confirma-se nestas passagens o que Rodrigo Patto intitula de "saneamento ideológico" da sociedade brasileira:

\begin{abstract}
"Anticomunismo não significa apenas um conjunto de opiniões divergentes em relação a um projeto político, mas um movimento, uma causa que mobilizou aderentes fervorosos, crentes que a salvação do país (e do mundo) dependia da repressão ao comunismo. Não se pode dizer que 0 anticomunismo seja uma doutrina, pois ele contém matrizes ideológicas diferentes, principalmente no caso do Brasil (catolicismo, nacionalismo e liberalismo), mas as representações nele inspiradas originaram uma tradição peculiar. $O$ histórico dos militantes é tido como primordial neste processo, baseando-se nas datas de ingresso no PCB, nas ações que realizaram junto aos sindicatos, nas prisões anteriores, e nas viagens ao exterior, em especial a Cuba". ${ }^{221}$
\end{abstract}

Um dos indiciados, Cícero Targino foi dirigente do combativo Sindicato dos Portuários, que também junto a outros sindicatos faziam parte do CONSINTRA. O Sindicato dos Portuários de Pernambuco tinha uma base de 1.300 portuários; 1.600 servidores autárquicos; 1000 estivadores; 200 conferentes e 600 marítimos (foguistas, marinheiros, taifeiros e moços de bordo).

Na direção do sindicato, Cícero Targino junto com outros tiveram uma participação decisiva contra a tentativa de golpe militar após a renúncia de Jânio Quadros em 1961.

Os golpistas, liderados pelos chefes das Forças Armadas e alguns governadores de Estados, como Carlos Lacerda do Rio de Janeiro, haviam tido o apoio em Pernambuco do governador Cid Sampaio, todos eram contra a posse de João Goulart para a Presidência da República.

O Governador Cid Sampaio colocou a polícia na rua, para reprimir e realizar centenas de prisões contra aqueles que saíssem em defesa da legalidade. A polícia militar invadiu o Sindicato dos Bancários, prendeu os dirigentes José Raimundo da Silva e Gilberto Azevedo e outros que estavam presentes. A

\footnotetext{
${ }^{221}$ MOTTA, Rodrigo Patto Sá. O anticomunismo e os órgãos de informações da ditadura nas universidades brasileiras. Contemporanea: Historia y problemas del siglo XX. Montevideo: Universidad de La República, Año 3, Volumen 3, p.133-148, 2012.
} 
polícia também encarcerou sindicalistas como David Capistrano do PCB sendo levado depois ao IV Exército, assim como outros ligados ao CONSINTRA e ao Sindicato dos Comerciários. Houve cerco a Faculdade de Direito e foi fechada a sede da União dos Estudantes de Pernambuco (UEP).

Houve resistências por toda parte no Recife, os estudantes saíram às ruas para panfletar, fazer pichações e realizar comícios relâmpagos a favor da legalidade. O CONSINTRA junto com a UEP organizaram comícios na Avenida Dantas Barreto, e convocaram greve geral a favor da Constituição e das liberdades democráticas.

Os portuários realizaram uma grande greve de tempo indeterminado, assustando as forças conservadoras do Estado e parando a circulação de mercadorias. Sob a liderança de Cícero Targino, os portuários e estivadores informaram ao comando do IV Exército a reivindicação de liberdade aos presos políticos, a única condição para que voltassem ao trabalho. A reivindicação foi atendida e muitos líderes sindicais foram recebidos nos sindicatos pelos trabalhadores.

Segundo o que consta no processo do procurador, Cícero Targino era $03^{a}$ secretário do comitê distrital do Porto, sendo responsável pela organização de base da estiva, das docas, dos arrumadores, dos marítimos e do moinho Recife. Viajou a Cuba em 1961 e fazia parte da fração parlamentar do PCB.

Cícero Targino foi deputado estadual pelo PST (Partido Social Trabalhista) - informações que 0 Procurador omite - apoiado pelo PCB, tanto ele quanto Gilberto Azevedo, dirigente do Sindicato dos Bancários. O outro candidato do PCB era David Capistrano, desaparecido político. Após o golpe de 64, cerca de 25 deputados tiveram seus mandatos cassados por ordem do Coronel Helio Ibiapina. O nome de Cícero Targino aparece em terceiro em ordem de prioridade dos perseguidos e processados pelo regime em Pernambuco, atrás de Miguel Arraes e Francisco Julião.

Já Cícero Gomes foi preso por ser membro do PCB, sendo reincidente de outra prisão em 1956 por agitações na fábrica da Macaxeira. João Messias era portuário e fazia parte da organização de base.

Sobre o Procurador, as informações que temos são de que Ananias Tavares lançou então um livro de memórias, Micro Memórias de um Octagenário Procurador de Justiça ${ }^{222}$ onde relata seus feitos "heroicos" como funcionário da justiça.

\footnotetext{
${ }^{222}$ CAMPOS, Ananias Tavares de Souza. Micro Memórias de um Octagenário Procurador de Justiça. Olinda: 2001.
} 
A aparência de um processo legal com conteúdo abertamente ideológico nos faz observar como se iniciava o longo caminho que a rede de informações tinha para ir se ramificando. Este documento depois que direcionado ao juiz, foi encaminhado ao chefe da Seção de Informações do Ministério da Justiça e Negócio Interiores (SI - MJNI), Odila Passos. O documento de conteúdo secreto, prontamente foi enviado ao Chefe da Agência Central do Rio de Janeiro do SNI, Coronel Golbery de Couto e Silva idealizador e criador do SNI.

Encontramos as referências de Cícero Targino até no Arquivo Público do DOPS (Departamento de Ordem Política e Social) de Minas Gerais, pedidos feitos pelo comando da $7^{a}$ Região Militar daquele Estado.

Em junho de 2012, o mandato de deputado estadual de Cícero Targino e de outros 25 deputados cassados foram restituídos ao cargo da legislatura simbolicamente, após 40 anos de espera.

Podemos fazer um esboço da construção da rede de informações de tal forma:

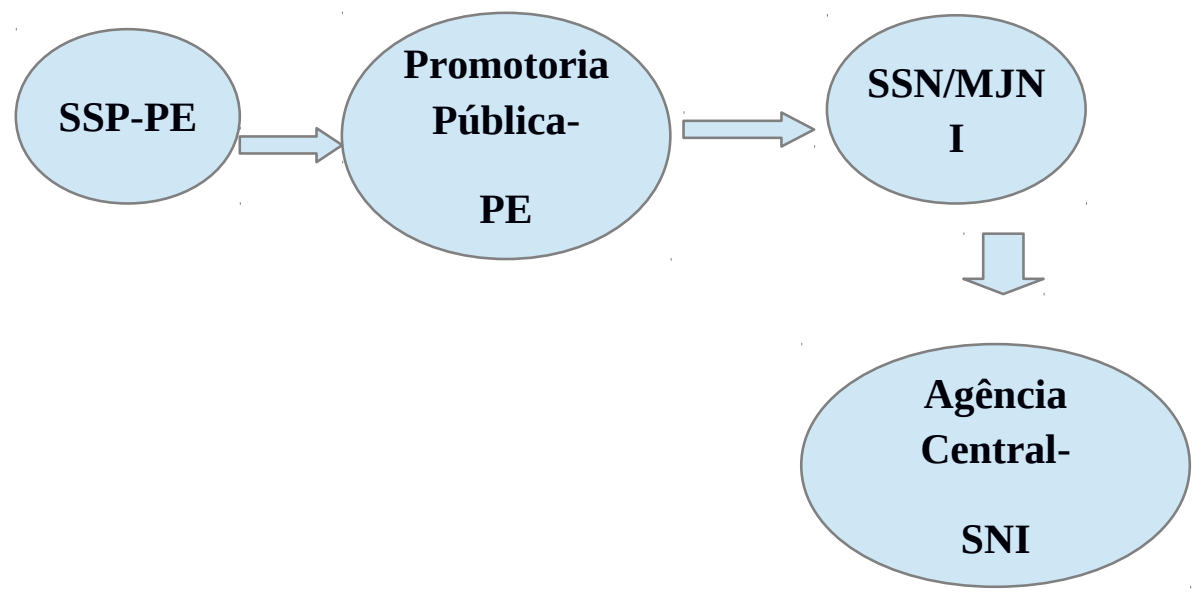

Outra investigação similar é feita sobre a participação dos bancários José Raimundo da Silva, Gilberto Azevedo, Aécio Flávio Correia, Ladário de Souza Filho, Rinaldo Claudino de Barros, Amaro Quintino Ferreira, Dirceu de Siqueira Cabral, Domicio Martiniano do Carmo, Antônio Tenório Marques e 
Joel Regueira Teodósio, na rearticulação do Comitê Bancário do Partido Comunista Brasileiro - Seção de Pernambuco, em Recife - 08/11/1965 223 .

Neste processo de 1965 produzido pela Secretaria de Segurança Pública do Estado de Pernambuco (SSP-PE), observamos a troca de informações direta com o restante da comunidade de informações. Esta movimentação agora se daria entre a SSP-PE, a Seção de Segurança Nacional do Ministério da Justiça e Negócios Interiores (SSN-NIMJ) e a Seção de Segurança Nacional do Ministério do Trabalho e Previdência Social (SSN-MTPS). Estes dois últimos órgãos são consultados sobre as informações complementares que poderiam ter sobre os sindicalistas presos.

Os sindicalistas perseguidos eram considerados sob a liderança dos bancários José Raimundo da Silva e Gilberto Azevedo. O primeiro se encontrava foragido e o segundo preso, são acusados de tentar reorganizar as bases do sindicato aproveitando-se da impunidade vigente. Segundo palavras do delegado Álvaro Gonçalves da Costa Lima, o documento inicia-se justificando os métodos utilizados pela polícia:

Com os depoimentos prestados pelos bancários que integram o grupo acima, depoimentos estes prestados de forma espontânea, natural, e detalhada, sem qualquer ameaça de torturas, métodos que não usamos, e quando invocados pelas defesas, já não impressionam, fácil é aquilatar-se 0 poder de penetração e persuasão dos comunistas. ${ }^{224}$

A prática da tortura durante os anos iniciais da ditadura em Pernambuco foi o método violento e desumano utilizado não apenas para conseguir informações sobre os opositores do regime, mas, sobretudo como descreveu o ex-deputado Márcio Moreira Alves ${ }^{225}$, era a "tortura pela tortura", um sentimento de sadismo, falta de escrúpulos e covardia, esta prática era conduzida pela vontade de poder em humilhar o opositor física e psicologicamente.

O ditador Castelo Branco por pressão de alguns setores da imprensa, que ainda não haviam sido fechados, e da Câmara de Deputados, com poucos que ainda não haviam sido cassados, criou uma Comissão de Investigação presidida pelo general Ernesto Geisel para ouvir os casos de "excessos" cometidos pelos agentes do Estado. Em Pernambuco, Geisel permaneceu por mais de 10 dias coletando os processos que porventura pudessem ter acontecido. Ouviu os opositores que estavam na prisão e apenas estes, e não os que já haviam sido torturados e soltos.

\footnotetext{
${ }^{223}$ BR.AN,RIO.TT.O.MCP.PRO.16.

${ }^{224}$ Idem.

${ }^{225}$ ALVES, Marcio Moreira. Torturas e Torturados. Rio de Janeiro: Editora Idade Nova, 1966.
} 
O ex-deputado Márcio Moreira entregou à Comissão de Investigação um relatório com mais de 30 casos de torturas apontando os torturados e torturadores, denunciando os vários agentes sob o comando do chefe da seção de inteligência do exército o coronel Antônio Bandeira, coronel Hélio Ibiapina, coronel Darcy Villocq, capitão Bismark, general Antônio Carlos Murici, e principalmente o delegado auxiliar Álvaro Costa "antigo torturador do Estado Novo e hoje responsável por servícias terríveis infligidas, sobretudo aos camponeses e trabalhadores"226, como os responsáveis pelos atos de tortura.

Seu livro Torturas e Torturados, trata em um de seus capítulos Nas prisões de Recife, sobre as entrevistas e denúncias que realizou e a permanência do estado de terror que foi instalado em Pernambuco. Relata sobre os policiais presos no quartel do Derby, sobre os sindicalistas e trabalhadores rurais que foram torturados nas delegacias, no IV Exército, na base da Marinha e na Aeronáutica, sobre os que foram jogados no Manicômio Judiciário. Reafirma seu relato a partir do texto produzido pela Comissão Civil de Investigação e pela Denúncia Coletiva dos Presos da Detenção de Recife.

Parte destas denúncias Geisel apresenta em um resumo com 23 laudas sobre as investigações de tortura em Pernambuco. Castelo Branco prontamente arquiva o documento e carimba como documento secreto. As denúncias de tortura serviram para reverter os fatos contra os próprios torturados, como consta no artigo do general Lyra Tavares do IV Exército do Recife no Jornal da Manhã em 1967:

Os teóricos da guerra revolucionária que pretendem explorar a credulidade pública atribuindo a elementos das forças armadas arbitrariedade e abusos de autoridade incompatíveis com a dignidade da função militar e do sentimento humano. ${ }^{227}$

Esta foi a forma como o regime achou em mascarar a realidade dos presos políticos e da prática de tortura no país. Ao negar a sua existência, transformava o denunciante como um inimigo aliado aos esquerdistas, tudo inserido na lógica da "guerra psicológica" aprendida nos manuais de formação militar.

Em sua obra, Fernando Bezerra ${ }^{228}$ expõe que nos primeiros dias do golpe de 64 em Pernambuco não havia celas suficientes para colocar a quantidade de presos que chegavam de todas as formas e lugares do estado para serem interrogados a partir de inúmeras denúncias sem fundamentos e/ou testemunhas.

\footnotetext{
${ }^{226}$ Idem.

${ }^{227}$ Idem.

${ }^{228}$ COELHO, Fernando Vasconcelos. Direita Volver: o golpe de 64 em Pernambuco. Recife: Ed. Bagaço, 2004.
} 
O relato do delegado e torturador Álvaro Costa Lima está dentro desta perspectiva, preocupa-se em redigir nos processos contra os militantes a ausência da prática da tortura, formalizando assim a distorção institucional do regime contra os direitos humanos:

O apagamento da memória coletiva das referências à tortura, bem como sua banalização, potencialmente reforçam as chances de naturalizá-la e ignorar a intensidade de seu impacto. 0 esquecimento é, nesse sentido, em si, uma catástrofe coletiva. ${ }^{229}$

Segundo o processo, Airton Alves recebia ordens sob orientação de José Raimundo para arregimentar jovens com a finalidade de reorganizar os comunistas no Sindicato dos Bancários. Com base em investigações onde perseguiam os militantes em praças e edifícios, se atesta que nestes lugares se realizavam reuniões com tais pretextos.

Algo similar observamos nos relatos do delegado em relação ao processo do procurador Ananias Tavares. O caráter ideológico de suas posições. A partir de premissas e conceitos abertamente anticomunistas, o delegado caracteriza as posições dos acusados, sobretudo pelas suas supostas aspirações conspirativas para derrubar o Movimento Revolucionário de 31 de março:

Diz-se, enfaticamente: ser comunista não é crime. A Constituição o permite. Certo. Mas, será que existe comunista para méro deleito pessoal, para uso estritamento interno? O que toda gente sabe e vê, é o comunista procurar de toda forma por em funcionamento as diretrizes do Partido Comunista: ajudá-los com serviço ou dinheiro, ostensiva ou clandestinamente, principalmente clandestinamente; fazer propaganda de seus princípios; distribuir panfletos tipo Combater; incitar as classes sociais à luta pela violência; endeusar os países socialistas. ${ }^{230}$

Segue-se após as considerações iniciais do delegado com suas opiniões políticas engajadas, os depoimentos de Rinaldo Claudino de Barros, Amaro Quintino Pereira, Dirceu de Siqueira Cabral, Ladário de Souza Filho, Domicio Martiniano do Carmo.

Podemos elencar tais pontos nos depoimentos dos 5(cinco) sindicalistas presos. Os relatos perpassam sobre vários acontecimentos, do tipo de envolvimento dos acusados com o PCB e quanto tempo atuaram em seus sindicatos. Alguns dos acusados tiveram participação no grupo literário Monteiro Lobato, enfatizado na interpretação do delegado como o meio que os comunistas iniciaram a

\footnotetext{
${ }^{229}$ SAFATLE, Vladimir e TELES, Edson (org.). O que resta da ditadura: a exceção brasileira. São Paulo: Editora Boi Tempo, 2010. p. 149.

${ }^{230}$ BR.AN,RIO.TT.O.MCP.PRO.16.
} 
propagandeação a partir dos encontros de leitura e da cultura literária. Eram funcionários do Banco do Brasil, e entre os anos de 1963-64 tiveram contato com o PCB, participando dos encontros no sindicato quando chamados.

Mas os objetivos centrais dos depoimentos eram: coletar mais nomes de dirigentes ligados ao PCB; reconhecer os membros do PCB que participaram do encontro municipal do partido nas matas de Camaragibe; e principalmente, o envolvimento dos dirigentes Gilberto Azevedo e José Raimundo dentro do sindicato e no partido.

Gilberto Azevedo era um dos dirigentes de maior relevância e reconhecimento pela sua atuação na organização sindical de Pernambuco entre os fins dos anos 50 e começo dos anos 60. Iniciando sua atuação na categoria foi o dirigente fundamental nas lutas de unidade com outras categorias sindicais, participou da criação do CONSINTRA (Conselho Sindical dos Trabalhadores), esteve como assessor no governo Miguel Arraes, e foi eleito deputado estadual pelo PST (Partido Social Trabalhista).

Ao voltar de Cuba em 1961, já como integrante do PCB, Gilberto Azevedo atuou na campanha pela legalidade, a favor da posse de João Goulart como Presidente e contra a tentativa de golpe por parte dos militares e alguns governadores golpistas. Uma forte mobilização havia se iniciado nas ruas do Recife. Junto com outros tantos sindicalistas dirigentes e estudantes foram presos por propagandear o direito de sucessão previsto na Constituição. Gilberto Azevedo e outros companheiros de sindicato, como José Raimundo (bancário e do PCB), Aluísio Falcão (Presidente do Sindicato dos Jornalistas) foram presos pelo Exército e levados para o Quartel das Cinco Pontas, logo depois, foram enviados para a prisão em Fernando de Noronha.

Em entrevista ao Centro de Estudos da História Brasileira (CEHIBRA), Gilberto Azevedo ${ }^{231}$ relata que no momento de sua prisão foi acompanhado por um oficial o qual ele reconhece como membro do Serviço Secreto do Exército. Podemos auferir algumas coisas sobre esta parte do depoimento de Azevedo. Ao dizer que conhecia o integrante do Serviço Secreto, naquela época então poderia ser membro do Serviço de Federal de Informações e Contra Informações (SFICI), ou da 2a Seção do Exército - E2. Por mais de uma passagem Azevedo se refere a esse oficial.

Azevedo e outros dirigentes foram soltos no mesmo ano de 1961 no dia de 7 de setembro, sendo recebidos pelos sindicalistas portuários e por milhares de trabalhadores, onde haviam realizado uma greve 
geral para o retorno dos presos políticos e da legalidade constitucional. Como observa Azevedo, aqueles momentos de tensão e perseguição foram um ensaio do que iria acontecer em 1964, com uma intensidade e brutalidade bem maior por parte dos militares.

Ao ser preso pela segunda vez após o golpe de 64, de ter tido cassado o mandato como deputado estadual e ter permanecido por mais de um ano na cadeia sendo solto por um habeas corpus do Supremo Tribunal Federal (STF), Azevedo faz um desabafo para o Coronel Ferdinando de Carvalho e o Major Amarante que o prenderam:

Olha coronel, quero dizer o seguinte, estou com habeas corpus expedido pelo Supremo Tribunal Federal e fui preso outra vez. Quero Ihe informar o seguinte: eu estava como deputado, quem fez o movimento subversivo não fomos nós, foi o Exército. Fui preso na Assembleia Legislativa, fui cercado. Não fugi. Fui para Fernando de Noronha, onde fiquei seis meses sem ter visitas. O IV Exercito mandou um ofício para essa delegacia exigindo que fosse cassado o meu mandato e ele foi cassado por cinquenta e quatro votos a um, foi o Almany Sampaio, que por isso teve 0 mandato cassado pelo Presidente da República. Fui demitido do Banco do Brasil. O Coronel Ibiapina fazia com que minha mulher saísse de casa, meia noite, uma hora, para entregar cartas e, às vezes, não entregava, rasgava diante dela. Então, estou solto agora e quero ver se reconstruo a minha vida, quer dizer, trabalhar e os senhores não me deixam. Então quero saber 0 seguinte: 0 que os senhores estão pretendendo de mim? ?32 $^{23}$

Podemos então avaliar o tipo de relação que havia entre o judiciário e o exército, uma relação que beirava a sobreposição de poder, a anulação da esfera do judiciário sob o executivo-militar, a ilegalidade constitucional e o estado de exceção.

Ao relatar sobre o CONSINTRA durante a entrevista, Azevedo explica como que esta entidade pertencente e criada pela necessidade de defesa dos interesses da classe trabalhadora em nível estadual, articulando-se com outras organizações em nível regional Nordeste e nacional, desempenhava um papel fundamental na unidade das lutas no estado de Pernambuco.

O princípio da solidariedade entre as categorias era a base da atuação da organização, não apenas solidariedade perante os sindicatos e movimentos urbanos, mas também junto ao movimento camponês como as Ligas Camponesas e os sindicatos rurais, e aos estudantes, era um ensaio de uma aliança entre o campo e a cidade. Quando havia um despejo de terra por parte dos usineiros ou da polícia, quadros do sindicato se dirigiam até o lugar para ajudar os camponeses. Havia uma ajuda nas mobilizações e a experiência da resistência ao golpe de 1961 foi parte disso.

\footnotetext{
${ }^{232}$ Idem.
} 
Porém quando eclode o golpe de 1964 no $1^{\circ}$ de abril, Azevedo coloca que havia uma confusão de informações que vinham por parte do governo federal, de Jango, e da imprensa. Os sindicatos rurais de Palmares e Goiana, e os sindicatos filiados ao CONSINTRA tentavam juntar forças com Miguel Arraes e as tropas policiais que não aderiram ao chamado golpista, porém o tempo de articulação foi curto e a voz de comando não viera.

O outro líder sindical que aparece como "fugitivo e perigoso dirigente comunista", José Raimundo da Silva, ingressou desde muito cedo nas fileiras do PCB, em 1950. Militando conjuntamente com Gilberto Azevedo, teve intensa participação nas lutas sociais em Pernambuco, dentro do sindicato dos bancários contribuiu para a construção da Federação dos Bancários Norte e Nordeste, Confederação dos Trabalhadores nas Empresas de Crédito - CONTEC, e no CONSINTRA.

Foi preso e enviado à ilha de Fernando de Noronha após a resistência ao golpe em 1961 junto com outros sindicalistas, após o golpe de 64 ficou na clandestinidade por anos, até ser preso e torturado no DOI/CODI do Rio de Janeiro em 1970. Foi solto em 1973 mesmo tendo sido condenado a 10 anos de prisão. Continuou atuando na organização sindical e na reconstrução do PCB, José Raimundo ${ }^{233}$ falece em 1 de outubro de 2011.

Desta forma podemos interpretar a construção da rede:

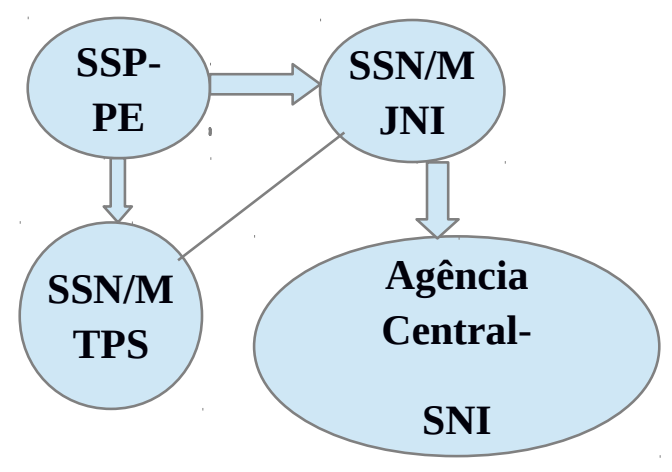

\section{EXPANSÃO DO SISTEMA}

\footnotetext{
${ }^{233}$ Central Única dos Trabalhadores - Rio de Janeiro (CUT). www.cutrj.org.br. Morre José Raimundo, bancário, militante e dirigente histórico da luta pelo socialismo. 02.10.2011.
} 
No contexto dos primeiros anos da ditadura militar, do governo Castelo Branco, o SNI serviria como centro aglutinador das informações que eram coletadas pelas estruturas mais diversas do Estado.

Ao considerar as fontes que apresentamos neste artigo, analisamos que tanto a Polícia Militar e 0 Judiciário em Pernambuco exerceram o papel de emissários de dados nos primeiros anos da repressão no envio de informações para o SNI. E que as Seções de Segurança Nacional do Ministério da Justiça, Trabalho e Transporte complementavam as informações que eram exigidas pela Agência Central do SNI no Rio de Janeiro.

A comunidade de informações entre os anos de 1964-1967 tinha por base a estrutura montada pelo Estado brasileiro antes do golpe de 1964. As Seções de Segurança Nacional criadas em 1937 no governo Vargas e reformuladas em 1946, pelo governo Dutra, foram as que deram suporte ao centro do sistema após 1964, o SNI.

As forças de repressão que prenderam militantes e perseguiram lideranças na tentativa de golpe em 1961 também foram as mesmas que com maior intensidade de força e organização estavam na linha de frente do golpe de 1964.

A comunidade de informações se expandia, com o Centro de Informações do Exército (CIE) criado em 1967, e da Aeronáutica, o Centro de Informações da Aeronáutica (CISA) criado em 1968. Aproveitando-se da antiga estrutura do serviço secreto do Exército e da Aeronáutica anterior a 1968, as chamadas $2^{\circ} \mathrm{S}$ (segundas) seções. O sistema demonstrava capacidade de aperfeiçoamento e profissionalização no combate ao sindicalismo, principalmente, pela atuação do SNI.

\section{BIBLIOGRAFIA}

ALVES, Marcio Moreira. Torturas e Torturados. Rio de Janeiro: Editora Idade Nova, 1966.

ANTUNES, Priscila Carlos Brandão. SNI \& ABIN: Uma leitura da atuação dos Serviços Secretos Brasileiros ao longo do Século XX. Rio de Janeiro: FGV editora, 2001.

BRASIL: NUNCA MAIS - UM RELATO PARA A HISTÓRIA. Petrópolis: Editora Vozes, ga edição, 1985.

CAMPOS, Ananias Tavares de Souza. Micro Memórias de um Octagenário Procurador de Justiça. Olinda: 2001.

COELHO, Fernando Vasconcelos. Direita Volver: o golpe de 64 em Pernambuco. Recife: Ed. Bagaço, 2004.

DREIFUSS, René Armand. 1964: a conquista do Estado - Ação Política, poder e golpe de classe. Petrópolis: Vozes, 1981. 
FERREIRA, Jorge (org). O populismo e sua história: debate à crítica. Rio de Janeiro: Civilização Brasileira, 2001.

FICO, Carlos. Como eles agiam. Rio de Janeiro: Record, 2001.

FUIGUEIREDO, Argelina C. Democracia ou reformas? Alternativas democráticas à crise política, 19611964. Rio de Janeiro: Paz e Terra, 1993.

FIGUEIREDO, Lucas. Ministério do Silêncio: A história do serviço secreto brasileiro de Washington Luís a Lula- 1927-2005. Rio de Janeiro: Ed. Record, 2005.

JACCOUD, Luciana de Barros. Movimentos sociais e crise política em Pernambuco - 1955-1968. Recife: Editora Massangana, 1990.

MELO, Demian Bezerra de (org). A miséria da historiografia: uma crítica ao revisionismo contemporâneo. Rio de Janeiro: Consequência, 2014

MOTTA, Rodrigo Patto Sá. O anticomunismo e os órgãos de informações da ditadura nas universidades brasileiras. Contemporânea: Historia y problemas del siglo XX. Montevideo: Universidad de La República, Año 3, Volumen 3, p.133-148, 2012.

QUADRAT, Samantha Viz. A preparação dos agentes de informação e a ditadura civil-militar no Brasil (1964-1985). Belo Horizonte: Varia História,v. 28, nº 47.

REIS, Daniel Aarão. Ditadura, anistia e reconciliação. Estudos Históricos. Rio de Janeiro: vol.23, n.45, p.171-186, jan/jun. 2010.

RIDENTI, Marcelo. Esquerdas revolucionárias armadas nos anos 1960-1970. In: Ferreira, Jorge e Reis, Daniel(org) Aarão. Revolução e democracia(1964-...). Rio de Janeiro: Civilização brasileira, 2007.

ROLLEMBERG, Denise (org). A construção social dos regimes autoritários. Brasil e América Latina. Rio de Janeiro: Civilização Brasileira, 2010.

SAFATLE, Vladimir e TELES, Edson (org.). O que resta da ditadura: a exceção brasileira. São Paulo: Editora Boi Tempo, 2010.

SANTANA, Marcos Aurélio. Homens partidos: comunistas e sindicatos no Brasil. São Paulo: Ed. Boitempo, 2001.

SILVA, Golbery do Couto e. Conjuntura política nacional: o poder executivo \& Geopolítica do Brasil. Rio de Janeiro: Ed. José Olympio, 1967.

SODRÉ, Nelson Werneck. O governo militar secreto. Rio de Janeiro: Ed. Bertrand Brasil, 1987.

\section{FONTES}

\section{Arquivo Nacional de Brasília}

Acervo do Sistema Nacional de Informações e Contrainformação - SISNI.

\section{Arquivo Nacional do Rio de Janeiro}

Fundo Divisão de Segurança de Informações/Ministério da Justiça e Negócios Interiores (DSI/MJ).

BR.AN,RIO.TT.0.MCP.15.

BR.AN,RIO.TT.0.MCP.PRO.16.

\section{Centro de Documentação e de Estudos da História Brasileira - CEHIBRA, Governo do Estado de Pernambuco \\ Entrevista com Cícero Targino. \\ Entrevista com Gilberto Azevedo.}

